\title{
Review
}

\section{A Review of Martial Arts and Bone Health Status in Young and Older Population}

\author{
Samsudin Norsuriani, MSc; Foong Kiew Ooi, PhD* \\ Exercise and Sport Science Programmes, School of Health Science, Universiti Sains Malaysia, Health Campus, Kelantan, Malaysia \\ *Corresponding author \\ Foong Kiew Ooi, PhD \\ Exercise and Sport Science Programmes, School of Health Sciences, Universiti Sains Malaysia, Health Campus, 16I50 Kelantan, Malaysia; E-mail: fkooi@usm.my
}

\section{Article information}

Received: August 19 th 2018 ; Revised: September $3^{\text {rd }}, 2018$; Accepted: September $7^{\text {th }}, 2018$; Published: September $7^{\text {th }}, 2018$

\section{Cite this article}

Norsuriani S, Ooi FK. A review of martial arts and bone health status in young and older population. Sport Exerc Med Open J. 20I8; 4(3): 58-62. doi: I0.I7I40/ SEMOJ-4-162

\section{ABSTRACT}

It is well known that mechanical loading imposed on a bone is important for bone development. Therefore, one of the most effective osteoporosis prevention strategies is by adopting weight-bearing physical activity. Martial arts such as judo, silat, karate, taekwondo and kickboxing are getting popular in recent years. It is generally known that bone's optimum response and adaptation to an applied load or strain during exercise are dependent on many factors, such as characteristics of the strain, i.e. static versus dynamic strain, strain magnitude, strain rate, strain frequency or duration, and distribution of the strain stimulus. It has been reported that martial arts are physical activities which can impose loads on the bone with their high and unusual distributed strains and subsequently increase bone health status of an individual. This article discusses the relationship between bone health and physical activity, types and characteristics of martial arts, and effects of various types of martial arts on bone health in young and older population.

Keywords

Bone; Physical activity; Martial arts.

\section{BONE HEALTH AND PHYSICAL ACTIVITY}

Bone is a metabolically active tissue that undergoes a continuous remodelling throughout its life cycle. The endogenic factors which can influence the accumulation of bone mineral in humans are heredity, ethnicity, gender and endocrine status. Meanwhile, the exogenic factors are nutrition and physical activity. ${ }^{1,2}$

Peak bone mass is attained during the second and third decades of life. Sports participation can lead to adaptive changes that improve bone architecture through increased density and enhanced geometric properties. ${ }^{3}$ Hara et $\mathrm{al}^{4}$ suggested that physical activities are the strongest determinant of high peak bone mass in young adults at pre-puberty and puberty. Furthermore, physical activity begun during the teenage years could also be useful for preventing osteoporosis and improving future quality of life of an individual.

It has been reported that weight-bearing sport activities are associated with a high bone mass in the lumbar spine, hip, femur, proximal tibia, and calcaneus. ${ }^{5,6}$ It has also been reported that different types of physical activity create different strain demands on the skeletal bones. ${ }^{6,7}$ In addition, Lanyon ${ }^{8}$ mentioned that mechanical loading imposes on a specific bone site should produce high strains in unusual patterns during short periods with high repetition for obtaining the greatest osteogenic effect.

According to Haapasalo et $\mathrm{al}^{9}$ loading exercises enhance bone mass, and it is necessary to have more weight on bones than common weights that occur in daily life. The osteogenic responses on the skeleton are specific to the region of mechanical stress, and the responses can be triggered by exercises.Exercise can increase the rate of osteogenesis and subsequently increase bone mineral density (BMD).

Robling et $\mathrm{al}^{10}$ stated that optimum response and adaptation of bone to an applied load or strain during exercise depends on many factors, which are characteristics of the strain, i.e. static 
versus dynamic strain, strain magnitude, strain rate, strain frequency or duration, and distribution of the strain stimulus. In addition, high impact dynamic loading activities, which involve high bone strain magnitude, rate, and with short duration of repeated bone loading and/or versatile strain distribution can provide large osteogenic stimulus in humans. ${ }^{6}$ Uneven distribution of the strain seems to have a higher potential for increasing osteogenesis. ${ }^{5,11}$ Moreover, the adaptive response of bone decreases after a few loading cycles. $^{12}$

\section{INTRODUCTION OF MARTIAL ARTS}

In ancient times, martial arts were practiced for self-defence, however, nowadays they are practiced for improvement in physical fitness level as well. ${ }^{13}$ According to $\mathrm{Bu}$ et $\mathrm{al}^{14}$, there are about 200 distinct disciplines of martial arts, and different facets of disciplines make them unique and special. All these disciplines share a common goal, i.e. to defend oneself from physical threat. Nowadays, martial arts are studied for various reasons, including fitness and self-defence enhancement, mental discipline, character development, and as a complementary or alternative therapy for some medical conditions. ${ }^{15}$ Martial arts is popular in many cohorts in terms of health promotion. For example, elderly persons can gain health benefits by performing tai chi exercise. ${ }^{16,17}$

Traditional styles of martial arts can be classified as either "soft" or "hard". The 'soft' martial arts are based on redirecting the opponent's energy or attack and less powerful in punching and kicking actions, whereas the 'hard' martial arts are based on using blocks and punches that can crush bones or body parts of an enemy. Hard martial arts deliver significantly more powerful strikes and rigid stances. ${ }^{18}$

The term martial art is often used to describe many of the combat arts that have been developed in eastern cultures, and most of the martial arts practiced in the United States are those that originated or evolved in China, Korea, and Japan. ${ }^{14}$ The martial arts of 'wushu' which originated in China include kungfu and tai chi chuan. Japanese martial arts include aikido, karate, sumo and judo. Taekwondo which was developed in Korea is a popular martial art nowadays, perhaps the most prevalent of the martial arts in the United States. Many other forms of martial arts have evolved throughout the world, such as silat (Malaysia), Muay Thai (Thailand), Pencak silat (Indonesia), Bando (Burma), Copoiera (Brazil) and Kahli (Philippines). ${ }^{14}$

\section{EFFECTS OF MARTIAL ARTS ON BONE HEALTH -}

In a study conducted by Shin et $\mathrm{al}^{19}$ which determined the effects of taekwondo training on the bone health status of high school female students with aged 13 to 17-years old in Korea, it was found that the average BMD in the taekwondo group was significantly greater than the sedentary control group for all lumbar spine regions. It was approximately 15\% higher in the lumbar spine and $17 \%$ higher in the femoral neck, which identified that taekwondo could improve bone health. Therefore, the authors mentioned that intermittent taekwondo activity as weight-bearing exercise should be recommended to increase BMD in adolescent females during growth. In addition, the authors also mentioned that their study findings support the concept that high strain rates and high peak stresses are more effective in enhancing bone formation than a large number of low-force repetitions.

Kim et $\mathrm{al}^{20}$ carried out a study to determine the effects of judo practice on the bone health status of high school male students with mean age of 17.2-years old in Korea. In this previous study, the boys who had engaged in judo practice had greater $\mathrm{BMD}$ in their lumbar, femur, and wrist regions when compared with their non-active subjects. According to the results of this study, the BMD was approximately $22.7 \%$ higher in the lumbar spine, $24.5 \%$ higher in the femur and $18.3 \%$ higher in the forearm of judo players when compared to sedentary control group. The authors mentioned that judo involves both high intensity and high strain rates, which strongly stimulate bone formation. Specifically, unusual strain distribution and versatile loading patterns, both are involved in the practice of judo for promoting bone mineralization with greater effects compared to exercises involve regular loading patterns. Therefore, the authors suggested that judo activity is strongly recommended to improve bone health and prevent osteopenia in young Korean males.

A previous study has been carried out by Ito et $\mathrm{al}^{21}$ to investigate the relationship between martial art practice of judo, karate and kungfu with bone mineral density in adolescents with age between 11 to 17 -years-old in both sexes. Their study showed that adolescents engaged in judo practice exhibited higher values of BMD in the arms compared to karate and kungfu participants. The authors also mentioned that muscle mass and biological maturation have been verified as important factors in bone mass and geometry gain.

A recent study conducted by Norsuriani and $\mathrm{Ooi}^{22}$ examined bone health status of Malay adolescent female silat and taekwondo practitioners with age ranged from 15 to 19-years-old. They found that there were no significant differences in quantitative ultrasound measurement of the bone speed of sound (SOS) of dominant and non-dominant arms and legs of young females among sedentary control, silat and taekwondo groups. In this study, the average age of the participants was 17-years-old, all the participants were Malay females, and their average duration of involvement in martial arts was 2 to 3 -years. It is speculated that differences in gender, age, ethnicity, duration of involvement in martial art training may have caused the inconsistent results of this study compared to the aforementioned previous studies.

Drozdzowska et $\mathrm{al}^{23}$ examined skeletal status assessed by quantitative ultrasound measurement (QUS) at the hand phalanges in 226 karate male practitioners between 7 to 61-years of age, who had been training karate for at least 6-months. The results showed that there were significant differences in bone mineral density of karate athletes compared with control subjects. The authors mentioned that longer duration, higher frequency, and early involve- 
ment in physical training positively influenced the skeletal status. They concluded that karate is a sport which can elicit a positive influence on the skeletal status, with the most significant benefits occurring in adults.

Andreoli et $\mathrm{al}^{24}$ investigated the effects of different sports including martial arts on bone density and muscle mass in highly trained athletes. In their study, participants consisted of judo $(n=21)$, karate $(n=14)$, and water polo $(n=24)$ men athletes with age ranged between 18 to 25 -years-old who competed at national and international levels, and age-matched non-athletic individuals were served as the control group. Their study found that athletes had significantly greater BMD than the non-athletes of similar age and in particular, the judo athletes, who practicing a high-intensity weight-bearing sport, had higher values of BMD compared to other athletes. Therefore, the authors highlighted that physical activity appears to have a beneficial effect on bone mass, with greater mechanical loading appears to result in a greater bone mass, and these appeared to be a site-specific skeletal response to the type of loading at each BMD site.

Agostinete et $\mathrm{al}^{25}$ investigated the effect of karate, judo, soccer and basketball on bone mineral density (BMD) accrual among male adolescents with age ranged from 11 to 17 -yearsold. In this previous study, it was observed that karate and judo groups exhibited higher BMD than soccer, basketball and control groups. Their findings are consistent with results of previous studies $^{26,27}$ which showed that impact sports could enhance bone health among adolescents. The authors mentioned that it is an indicator of responsive loaded sites to the significant amount of mechanical loads induced by martial arts training. The authors also mentioned that during punching, kicking, blocking and striking in martial arts, loading bones are under tensile, compressive, shear, bending, and torsional stress, which produces high strain stimulus for eliciting beneficial effects on bone.

A study was conducted by Platen et $\mathrm{al}^{28}$ to determine bone mineral density in top-level male athletes of different sports, i.e. athletics, cycling, team sport, judo and wrestling. The participants of this study aged between 18 to 31-years. Among 173 athletes participants, 104 were athletes of runners $(n=21)$, cyclists $(n=12)$, triathletes $(n=18)$, heavy athletes such as judo and wrestling $(n=28)$, and team sport athletes (handball, soccer, basketball, volleyball, $\mathrm{n}=25) ; 44$ were not specifically trained sport students and 25 were untrained controls. This previous study found that at most sites, BMD was highest in heavy athletes (judo and wrestling) followed by athletes in team sports and sports students, and lowest in cyclists and untrained controls. An explanation for these results is that the strain imposed on bone is mainly determined by mechanical forces, and dynamic forces depend on the body mass and acceleration. In judo and wrestling, movements correspond to high maximal muscular strength and power. Besides forces induced by muscular activation, high accelerations and therefore high forces, as well as varied patterns of strain, occur when falling in judo and wrestling. Furthermore, special strength training with heavy weights is a typical and regular training method in these sports. Therefore, high bone formation rate can be expected by involvement in judo and wrestling.

Soo bahk do (SBD; also known as tang soo do) emphasises a combination of hard styles of karate and tae kwon do with the soft style of the Chinese martial arts. Their system of action and the characteristic use of bare hands and feet as striking weapons are different from other martial art systems. A study carried out by Douris et $\mathrm{al}^{29}$ examined fitness levels of middle-aged martial art practitioners in both genders from 40 to 60 -years of age. The study found that the SBD practitioners were higher in bone health status compared to sedentary participants. The authors mentioned that SBD can be considered an excellent form of exercise for the promotion of fitness in middle-aged population.

Ving T sun (VT) is a traditional Chinese martial art that has the potential to be developed into a new form of healthmaintenance exercise to prevent bone loss in the elderly. Fong et $\mathrm{al}^{30}$ compared bone strength, lower limb muscular strength, functional balance performance, and balance self-efficacy between VT martial art practitioners and non-practitioners with mean age of 62.7- years-old in both sexes. In their study, it was found those VTtrained older adults had the significantly higher bone strength than the control group. VT training includes many striking movements using the forearms, for example, sandbag workouts, sticking-hand exercises, and wooden dummy training, and therefore the authors concluded that these movements repetitively load the forearm bones including the radius with high impact forces, resulting in remodeling and strengthening of these bones to withstand the external loads or stress.

Tai Chi is a traditional Chinese mind-body exercise and benefits on health outcome, particularly middle-aged and elderly people. A study conducted by Hui et a ${ }^{31}$ which determined the effects of Tai chi on bone mineral density (BMD) in both genders of Chinese adults with aged from 36 to 60 -years-old. The study found that there was no significant change in BMD of both groups, i.e. Tai Chi and control groups. These authors concluded that shortterm Tai Chi exercise, e.g., 12-weeks may not provide sufficient training stimulation in improving bone health, and may can only be acted as a protective factor for bone loss in older population.

\section{CONCLUSION}

Previously published research studies on martial arts mentioned in this article provide evidence that involvement in training and competition of martial arts such as taekwondo, judo, karate, wrestling, soo bahk do, Ving T sun and Tai Chi could elicit beneficial effects on bone health in young and older population. Thus, it can be concluded that engagement in martial arts is one of the effective ways to enhance bone health.

\section{CONFLICT OF INTEREST |}

The authors declare that they have no conflicts of interest. 


\section{REFERENCES}

1. Javaid MK, Cooper C. Prenatal and childhood influences on osteoporosis. Best Pract Res Clin Endocrinol Metab. 2002; 16: 349-351. doi: 10.1053/beem.2002.0199

2. Rizzoli R, Bianchi ML, Garabedian M, McKay HA, Moreno LA. Maximizing bone mineral mass gain during growth for the prevention of fractures in the adolescents and the elderly. Bone. 2010; 46: 294-305. doi: 10.1016/j.bone.2009.10.005

3. Tenforde AS, Fredericson M. Influence of sports participation on bone health in the young athlete: A review of the literature. PM R. 2011; 3: 861-867. doi: 10.1016/j.pmrj.2011.05.019

4. Hara S, Yanagi H, Amagai H, et al. Effect of physical activity during teenage years, based on type of sport and duration of exercise, on bone mineral density of young premenopausal Japanese women. Calcif Tissue Int. 2001; 68: 23-30. doi: 10.1007/s002230001179

5. Fehling PC, Alekel L, Clasey J, Rector A, Stillman RJ. A comparison of bone mineral densities among female athletes in impact loading and active loading sports. Bone. 1995; 17: 205-210.

6. Heinonen A, Oja P, Kannus P, et al. Bone mineral density in female athletes representing sports with different loading characteristics of the skeleton. Bone. 1995; 17: 197-203.

7. Slemenda CW, Johnston CC. High intensity activities in young women: Site specific bone mass effects among female figure skaters. Bone Miner. 1993; 20: 125-132.

8. Lanyon LE. Control of bone architecture by functional load bearing. J Bone Miner Res. 1992; 7: 369-375. doi: 10.1002/ jbmr.5650071403

9. Haapasalo H, Kannus P, Sievanen H, et al. Long-term unilateral loading and bone mineral density and content in female squash players. Calcif Tissue Int. 1994; 54(4): 249-255.

10. Robling AG, Burr DB, Turner CH. Partitoning a daily mechanical stimulus into discrete loading bouts improve the osteogenic response to loading. J Bone Miner Res. 2000; 15: 1596-1602. doi: 10.1359/jbmr.2000.15.8.1596

11. Judex S, Rubin C. Mechanical influences on bone mass and morphology. Osteoporosis. 2010; 181-205.

12. Umemura Y, Ishiko T, Yamauchi T, Kurono M, Mashiko S. Five jumps per day increase bone mass and breaking force in rats. J Bone Miner Res. 1997; 12(9): 1480-1485. doi: 10.1359/ jbmr.1997.12.9.1480

13. Burke DT, Al-Adawi S, Lee YT, Audette J. Martial arts as sport and therapy. J Sports Med Phys Fitness. 2007; 47(1): 96-102.
14. Bu B, Haijun H, Yong L, et al. Effects of martial arts on health status: A systematic review. J Evid Based Med. 2010; 3(4): 205-219. doi: 10.1111/j.1756-5391.2010.01107.x

15. Sharpe PA, Blanck HM, Williams JE, Ainsworth BE, Conway JM. Use of complementary and alternative medicine for weight control in the United States. J Altern Complement Med. 2007; 13(2): 217-222. doi: 10.1089/act.2007.13407

16. Verhagen AP, Immink M, Meulen VDA, Bierma-Zeinstra SM. The efficacy of Tai Chi Chuan in older adults: A systematic review. Fam Pract. 2004; 21(1): 107-113.

17. Zeeuwe PE, Verhagen AP, Bierma-Zeinstra SM, et al. The effect of Tai Chi Chuan in reducing falls among elderly people: Design of a randomized clinical trial in the Netherlands. BMC Geriatr. 2006; 6: 6. doi: 10.1186/1471-2318-6-6

18. Donovan OO, Cheung J, Catley M, et al. An investigation of leg and trunk strength and reaction times of hard-style martial arts practitioners. J Sports Sci Med. 2006; 5-12.

19. Shin YH, Jung HL, Kang HY. Effects of taekwondo training on bone mineral density of high school girls in Korea. Biology of Sport. 2011; 28: 195-198. doi: 10.5604/959288

20. Kim PS, Shin YH, Noh SK, et al. Beneficial effects of judo training on bone mineral density of high school boys in Korea. Biol Sport. 2013; 30: 295-299. doi: 10.5604/20831862.1077556

21. Ito IH, Mantovani AM, Agostinete RR, et al. Practices of martial art and bone mineral density in adolescent of both sexes. Rev Paul Pediatr. 2015; 34(2): 210-215. doi: 10.1016/j.rppede.2015.09.003

22. Norsuriani S, Ooi FK.. Bone health status, isokinetic muscular strength and power, and body composition of Malay adolescent female silat and taekwondo practitioners. International Journal Public Health and Clinical Science. 2018; 5(2): 224-262.

23. Drozdzowska B, Munzer U, Adamczyk P, Pluskiewicz W. Skeletal status assessed by quantitative ultrasound at the hand phalanges in karate training males. Ultrasound Med Biol. 2011; 37: 214-219. doi: 10.1016/j.ultrasmedbio.2010.10.023

24. Andreoli A, Monteleone M, Van Loan M, et al. A.Effects of different sports on bone density and muscle mass in highly trained athletes. Med Sci Sports Exerc. 2001; 33(4): 507-511.

25. Agostinete RR, Lynch KR, Gobbo LA, et al. Basketball affects bone mineral density accrual in boys more than swimming and other impact sports: 9-mo follow-up. J Clin Densitom. 2016; 1-7. doi: 10.1016/j.jocd.2016.04.006

26. Egan E, Reilly T, Giacomoni M, et al. Bone mineral density among female sports participants. Bone. 2006; 38: 227-233. doi: 10.1016/j.bone.2005.08.024 
27. Quiterio ALD, Carnero EA, Baptista FM, Sardinha LB. Skeletal mass in adolescent male athletes and non-athletes: relationships with high-impact sports. I Strength Cond Res. 2011; 25: 3439-3447. doi: 10.1519/JSC.0b013e318216003b

28. Platen P, Chae EH, Antz R, et al. Bone mineral density in top level male athletes of different sports. European Journal of Sport Science. 2001; 1(5): 1-15. doi: 10.1080/17461390100071501

29. Douris P, Chinan A, Gomez M, et al. Fitness levels of middle aged martial art practitioners. Br J Sports Med. 2004; 38: 143-147.
30. Fong SSM, Ng SSM, Liu KPY, et al. Musculoskeletal strength, balance performance, and self-efficacy in elderly VingTsun Chinese martial art practitioners: Implications for fall prevention. Evidence-based Complementary and Alternative Medicine. 2014; 6.

31. Hui SSC, Xie YJ, Woo J, Kwok TCY. Effects of tai chi and walking exercises on weight loss, metabolic syndrome parameters, and bone mineral density. Evidence-Based Complementary and Alternative Medicine. 2015; 1-10. doi: 10.1155/2015/976123 